\title{
A values-based phenomenology for substance use disorder: a new approach for clinical decision-making
}

\author{
Uma fenomenologia baseada em valores nos transtornos por uso de \\ substâncias: uma nova abordagem para a tomada de decisão clínica
}

\author{
Guilherme MESSAS ${ }^{1}$ \\ $0000-0002-8985-2300$ \\ Kenneth FULFORD ${ }^{2}$ iD) 0000-0002-3141-9328
}

\begin{abstract}
Phenomenological psychopathology has been defined as a human science that is concerned with the object on which clinical psychology and psychiatry act. How psychopathological experiences are understood is an important factor determining decision-making in clinical care. An accurate understanding of psychopathology is fundamental to the effectiveness of mental health treatments. This is even more important in a field such as substance use disorders in which social and cultural values influence both diagnosis and decision-making. In this article, we offer a contribution to clinical decision-making in substance use disorders by suggesting the association of Phenomenological Psychopathology and Values-Based Practice, constituting a Values-based Phenomenology We present a fictitious clinical case (to preserve confidentiality), illustrating a three-step practical application of Values-based Phenomenology. We conclude that although still a nascent discipline, Values-based Phenomenology offers a promising approach to reducing the gap between services and patients' needs in clinical decision-making, and thus to improving clinical care in substance use disorders.
\end{abstract}

Keywords: Alcoholism; Alcohol-related disorders; Phenomenology; Phenomenological psychopathology; Values.

\section{Resumo}

A psicopatologia fenomenológica é uma ciência humana que define o objeto sobre o qual atuam a psicologia clínica e a psiquiatria. O modo como são compreendidas as experiências psicopatológicas é um fator importante nas tomadas de decisão clínica. Uma compreensão acurada de psicopatologia é fundamental para a efetividade dos tratamentos em

1 Santa Casa de Sao Paulo, Faculdade de Ciências Médicas, Programa de Pós-Graduação em Psicopatologia Fenomenológica. R. Dr. Cesário Motta Jr., 61, Vila Buarque, 01221-020, São Paulo, SP, Brasil. Correspondence to: G. MESSAS. E-mail: <guilherme. messas@fcmsantacasasp.edu.br>.

2 University of Oxford, St Catherine's College, Collaborating Centre for Values-based Practice in Health and Social Care. Oxford, United Kingdom.

$\nabla \nabla \nabla$

How to cite this article

Messas, G. \& Fulford, K. (2021). A values-based phenomenology for substance use disorder: a new approach for clinical decision-making. Estudos de Psicologia (Campinas), 38, e200102. https://doi.org/10.1590/1982-0275202138e200102 
saúde mental. Isso é mais importante ainda em um campo como o dos transtornos por uso de substâncias, no qual há um importante imbricamento entre valores sociais e culturais. Neste artigo, se oferece uma contribuição para as tomadas de decisão clínica nos transtornos por uso de substâncias por meio da associação entre a psicopatologia fenomenológica e a Prática Baseada em Valores, constituindo uma fenomenologia baseada em valores. Apresenta-se um caso clínico fictício (visando à preservação de confidencialidade) ilustrativo dos três passos da aplicação prática da fenomenologia baseada em valores. Conclui-se que a fenomenologia baseada em valores constitui uma abordagem promissora para o aprimoramento das tomadas de decisão clínica nos transtornos por uso de substâncias.

Palavras-chave: Alcoolismo; Transtornos relacionados ao uso de álcool; Fenomenologia; Psicopatologia fenomenológica; Valores.

Phenomenological Psychopathology has been defined as the human science that is concerned with the object of psychological and psychiatric clinical care (Messas, Tamelini, Mancini, \& Stanghellini, 2018). The therapeutic strategy adopted for a given clinical case depends critically on how the disturbed experience of the person in question is understood. In this respect, it can be said that psychopathology is a founding discipline for the processes of clinical decision-making and of establishing the criteria for evaluating therapeutic success or failure. Therefore, it is essential that a clear definition of the psychopathological concepts with which a clinician operates precede any discussion of strategies for mental health care.

This general condition is particularly relevant in the case of Substance Use Disorders (SUD). In this field, the limits between normal and altered experiences are diffuse, favoring superficial interpretations of the phenomena, which can lead to harmful repercussions for the people who use the substances in question and suffer consequential harms. These harmful consequences can extend to areas that go far beyond clinical insufficiency or incompetence, reaching basic principles of contemporary societies, such as human rights. A common example is the different attitude society has towards a person who abuses substances, according to their diagnostic status. The identification by a clinician of the validity of a psychopathological state favors a more positive societal attitude toward that person, while an interpretation, for example, moralistic, accentuates the frequent stigma that plagues this population. The most recent attempts to support substance abuse-related diagnoses on a more solid and more objective basis have been quite disappointing, if not counterproductive (Arria \& McLellan, 2012). Many commentators (including some of those working in the neurosciences) have argued that the broad use of neuroscientific concepts and knowledge as markers of diagnostic certainty that could provide this foundation have not provided the desired results, either in terms of improved services or reduced stigma (Cuthbert, 2014; Hall, Carter, \& Forlini, 2015; Kupfer, First, \& Regier, 2002). The universally accepted criteria for SUD continue to consist of a mixture of subjective elements (e.g., craving for substance use), behavioral elements (e.g., narrowing of the drinking repertoire) and biological elements (tolerance and abstinence) (American Psychiatric Association, 2013; World Health Organization, 1999). Although these criteria are able to cover, in a generic way, the majority of problematic experiences, they do not shed much light on the specific differences among the ways in which people, in their daily realities, actually experience them (Leal, Muñoz, \& Serpa, 2019). Their application depends on subjective criteria that cannot be defined objectively - as, for instance, what a person or a social group understands by restriction of the drinking repertoire is by no means universal. Some social groups may even have an attitude that positively values routine alteration of the state of consciousness (Messas \& Soares, 2021).

It is, therefore, the specifics of each clinical case, scientifically captured through implicit values within the scientific categories of thought, that determine mental health decision-making. In the same way, the interpretations that each clinician, each patient, and each family member gives to the substance abuse greatly influence the decision-making processes. It is not uncommon for different clinicians to propose different and even conflicting referrals in situations of substance abuse that are similar, from a descriptive or behavioral point of view. Adopting a diagnostic tool that is capable of accurately capturing the ways in which people 2 experience their substance abuse is therefore central to the decision-making processes in this mental health field. 
Phenomenological Psychopathology (PhP) is a branch of psychopathology that seeks to explore the conditions of possibilities of experiences (Fuchs, Messas, \& Stanghellini, 2019). Originally conceived as a descriptive psychopathology of subjective experiences (Jaspers, 1997), PhP has gradually deepened its object of interest, seeking to reach the subjective and intersubjective structures that underpin human existence (Messas, 2014a). Especially in the last two decades, the social and scientific relevance of this discipline has increased all over the world, as can be seen with the publication of the Oxford Handbook of Phenomenological Psychopathology (Stanghellini et al., 2019). As a procedure that investigates the structure of existence, Phenomenological Psychopathology has been expanding its sphere of application in the field of mental health, inspiring developments in phenomenological clinical care, its use becoming widespread in both the psychotherapeutic (Cury, 2016; Holanda, 2016; Moreira, 2013) and psychiatric dimensions (Tamelini \& Messas, 2017, 2019).

Phenomenological Psychopathology contribution to SUD is still somewhat limited, although there have been a number of relevant initiatives in that sense (Di Petta \& Tittarelli, 2019; Kemp \& Butler, 2014; Messas, 2014b, 2015, 2021; Messas, Fukuda, \& Pienkos 2019; Pringuey, 2005). The phenomenological exploration of SUD is thus more of a scientific frontier than of a consolidated ground. An emerging and promising field for the application of Phenomenological Psychopathology as an instrument to increase clinical effectiveness in SUD care, is its association with the Values-Based Practice (VBP), as we will argue in the next section.

\section{Values-Based Practice and clinical decision-making}

Diagnoses in mental health are loaded with value-led decisions, most often implicit (Fulford, 1989/1999; Fulford, Broome, Stanghellini, \& Thornton, 2005; Sadler, 2005). Take, for example, the classic case of the psychopathological diagnosis of homosexuality, which formerly belonged to the set of mental disorders. Nowadays, with the cultural changes that have rapidly allowed the reduction of the stigma linked to sexual conducts and gender identities, it seems natural to the scientific community that this existential condition figures among the variations of normality.

In the same way, decision-making is heavily charged with assumptions which, in certain clinical situations, are/may be more important than the criteria on which a psychopathological condition is defined. For example, it is expected that society will interpret the alcohol abuse of an underage person differently from the same condition for, say, someone in their 40s. Although in diagnostic terms both may be similar, they immediately imply different decision-making. One would expect the clinician or society not to tolerate the abuse (or the use) of the former and to show greater tolerance towards the latter. Only valuation differences in the interpretation of the meaning of use in each case would justify a firm prohibition in the first case and leniency in the other. This difference in attitudes would be based on the understanding, by contemporary societies, that alcohol abuse in an adolescent may lead to brain injuries or even behavioral injuries that the underage person is unable to choose for him or herself. In the case of adults, although there is much difference among societies about the acceptable limits for substance abuse, there is certainly no absolute refusal of the idea that they can decide in part on a self-inflicted conduct, as long as it does not cause harm to others.

The importance of understanding the role of personal values in clinical decision-making has been increasingly recognized in the United Kingdom (UK) since the establishment in 2003 of a Values-Based Practice program in the UK's Department of Health (under the auspices of its then policy implementation section, the National Institute for Mental Health in England) (Fulford, Dewey, \& King, 2015)․ Values-Based

\footnotetext{
$\boldsymbol{\nabla} \mathbf{v} \boldsymbol{v}$

${ }^{3}$ For full details of all aspects of the theory and implementation of contemporary values-based practice, please see the website for the Collaborating Centre for Values-based Practice in Health and Social Care, St Cathernine's College, University of Oxford, UK at: $<$ valuesbasedpractice.org $>$.
} 
Practice has since been developed as a decision support tool that works as a partner to Evidence Based Practice in all areas of medicine and health sciences (Fulford, Peile, \& Carroll, 2012). Where Evidence-Based Practice provides a process that supports the balanced use of complex and sometimes conflicting evidence in clinical decision-making, VBP does the same for values. Values-Based Practice provides a process (based on learnable clinical skills and other key process elements) that supports the balanced use of complex and sometimes conflicting values in clinical decision-making.

Specifically in relation to SUD care, this means that VBP supports the incorporation of the different (and potentially conflicting) values of the various stakeholders involved in promoting the co-responsibility of the subjects directly involved in the care process: users, caregivers, clinical professionals, and managers. Values-Based Practice is not, therefore, a practice that presupposes judgment of the behavior of the other, but the establishment of care relationships permeated by respect between the parties. This is why VBP allows balanced decision-making (in both clinical and policy contexts) on procedures and care processes implemented in a democratic and consensual manner. Differences in values are potentially the cause of conflict, so, for applying VBP, there is a need to develop some practical skills based on theoretical concepts, that can minimize potential friction. Although VBP has been used for some time in the United Kingdom, there is no record of its application in the decision-making regarding the SUD clinical care.

The early development of VBP was based on the analytic philosophy of values (Fulford \& van Staden, 2013), but there has been growing recognition of the need to extend its theoretical base to incorporate insights from phenomenology and other areas of contemporary philosophy (Fulford \& Stanghellini, 2019). Since its inception, phenomenological philosophy has also evidenced the importance of values for the understanding of reality (Scheler, 1980). The incorporation of phenomenological insights into VBP - and of insights from VBP into phenomenology -, provides new opportunities to develop treatment approaches that benefit from accurate observation of the changes in the subjectivity structure associated with psychiatric disorders, using this to develop collaborative treatment approaches that reflect the values and experiences of patients and, thus, adjust the perceptions of subjective needs of mental health services to their provision. Moreover, evidence indicates that shared decision-making increases effectiveness in the treatment of SUD (Joosten, Jong, Weert-van Oene, Sensky, \& van der Staak, 2011).

The objective of this article is to advance the links between PhP and VBP and illustrate its potential applications to SUD. Building on this objective, and in line with recent publications on eating disorders (Stanghellini, Mancini, Castellini, \& Ricca 2018), schizophrenia (Stanghellini \& Ballerini, 2007), and other areas of psychopathology (Stanghellini \& Mancini, 2017; Stanghellini et al., 2019) that have used similar approaches, our aim is to offer initial elements for the constitution of a new discipline, Values-Based Phenomenology (VBPh). We believe that VBPh can contribute to improving clinical effectiveness in SUD, an area of public health that is still relatively neglected. We argue that attention to the aspects of experience highlighted by VBPh and the ways in which they are defined and treated by patients and caregivers, is essential for approaches that fully recognize the personality of mental health patients, leading to their greater empowerment, agency, and engagement in health care settings.

To illustrate how this method can be used in a clinical setting, we will present in the next section the story of "Marcos". As we describe further below, Marcos' is a fictitious case, although his story is based on many cases encountered by the authors in their careers. In Marcos' story, there is some controversy in clinical decision-making involving personal and family values and the interpretation of the existential meaning of substance use. We outline some of the pragmatic consequences of these controversies - including a three-step practical approach to clinical decision-making -, that the use of VBPh brings to the SUD approach.

We argue that in complex clinical situations such as that presented by Marcos, in which decision-making is difficult, VBPh shows promise as an instrument for dealing with dilemmas and existential complexities, 4 offering conceptual and practical tools to support informed, shared clinical decision-making. We will present 
in our case analysis some preliminary fundamental concepts of the functioning of VBPh, highlighting the way in which concepts derived from phenomenology can be associated, in a productive way, with those from VBP. We will highlight the usefulness of a combined VBPh as a guide for decision-making by the clinician, in shared action with the patient and relatives.

\section{The case of Marcos ${ }^{4}$}

Marcos is 50 years old and has a well-established professional career, which allows him a stable economic situation and a very comfortable life. Married, he is the father of two teenage daughters. Marcos has a long history of alcohol abuse, since he was 18 years old. His pattern of daily intake of high doses of ethanol has varied very little throughout his life. He recognizes his abuse and describes himself as an alcoholic. He adds, however, that he only knows how to live this way, that he likes to drink. He evaluates that he has achieved everything in life by being like this and, therefore, he would like to be aware of the damages of the drink, but without interrupting its use. Since his laboratory tests show no signs of damage caused by alcohol (except for slight cortical brain atrophy, possibly attributable to the use of alcohol), he is proud of his body's strength. Even when alerted to the risks that cannot be seen by laboratory tests, such as the high risk of stroke, heart disease and cancer, he does not change his position. He sought treatment to have a person with whom to share the difficulties of a stressful day-to-day life. He is a kind and cordial patient, sincere in the manifestations of his feelings, although intractable when it comes to alcohol abuse.

His family, however, disagrees with his optimism regarding the damaging effects of alcohol on him. His wife and one of his daughters report that drinking exposes him to many situations of social wear and tear (such as conflicts at work or inappropriate behavioral jocosity) and aggressive attitudes at home, occasionally amounting to marital violence. In addition, they say that Marcos is very repetitive in his themes and his habits; they fear that this restrictive behavior is caused by frequent intoxication. They say that Marcos' close friends share this opinion, but they do not know what to do about his behavior. They all fear that his professional situation may deteriorate if he continues with this lifestyle.

After much insistence from his family, Marcos underwent a neuropsychological evaluation to investigate possible alterations in his cortical functions. In the evaluation, important deficits were found in executive functions, incompatible with the demands of his work. In all probability, the deficits were not evident in his professional daily life due to his high intellectual capacity. The results of the test were presented to the patient and the family, leading to different suggestions for referral. Marcos disdains their importance, maintaining that they tell him nothing he did not already know. The family, on the other hand, receives them with extreme concern, demanding immediate measures from the patient to stop his drinking habit. His wife says that she cannot continue in the relationship if he does not do this, but Marcos refuses to take any action. It is important to stress that at no time had the patient demonstrated any cognitive disability that would impede or compromise his ability to make decisions.

\section{A three-step VBPh process}

In the next three subsections, we outline three basic steps in the exercise of VBPh as exemplified by Marcos' story: step 1, the analysis of conflicting values; step 2, a values-enriched phenomenological psychopathological understanding, and, finally, step 3, the process of clinical decision-making using VBPh.

$\boldsymbol{\nabla} \mathbf{\nabla}$

4 "Marcos" is a fictitious character but his story is based on those of a number of personal histories from the authors' extensive clinical experience. The events and other details of his story thus bear no relation to and are not intended to represent any person living or deceased. 
The three sections, taken together, illustrate the application of VBPh in SUD. We should emphasize, however, that any application of VBPh (like that of VBP itself) depends critically not just on what is done but on how it is done. Communication skills, in particular, including skills of listening, are crucial (Fulford et al., 2012). This is why we have chosen to illustrate how the three-step process works out in Marcos' case rather than presenting it as a direct continuation of his story. Our three-step process should not be understood as a procedure to be followed blindly. It is rather an outline for a process, the proper use of which in clinical decision-making requires the skills of a fully trained and appropriately experienced practitioner applied in a way that is sensitive to the particular values of the individual patient concerned.

\section{Step 1 - Analysis of conflicting values}

In his story, what Marcos values, above all, is the preservation of his personal will as a manifestation of his independence and autonomy. He supports this belief based on the fact that he attained his position as a successful professional through the ability to exercise his free will without any constraints. He interprets professional success as strong evidence of his ability to assess and control his own risks and to test them to their limits. Although he cares about his family's opinions, he does not guide his decision-making by their suggestions or even the ultimatum he received from his wife. He also places greater reliance on the objective test results that do not indicate significant current injury, than on the findings related to his cognitive state. This highlights Marcos' hierarchy of values in which his will prevails, both over family concerns and objective findings. This is an individualistic valuation of his SUD.

On the other hand, the family structures its decision-making regarding treatment from a collectivist perspective. They understand that their intervention is necessary and will have a salutary effect, as the patient is on the verge of seriously harming himself, in addition to the damage he has already inflicted on his family relationships.

On first reading Marcos' story, it may seem that his values, and the conflicts between him and his family, are obvious. But this is an illusion. In the context of everyday practice, clinicians all-too-often misread what is important to their patients, and this is why enhanced understanding of patients' values is central to values-based practice (Fulford et al., 2012). As in Marcos' story, the key values involved may be in part explicit and in part implicit. As to explicit values, values-based practice offers a range of skills including (as noted above) specific aspects of communication skills. Positive results with values-based training in these skills aimed at enhanced understanding of patients' values in other clinical areas (Handa et al., 2016) suggests that VBP training for those working with SUDs could be similarly productive. But (as in Marcos' case) many of the key values involved in a given patient's values hierarchy may be implicit rather than explicit in nature. These values have thus to be made explicit if they are to be balanced in a process of shared decision-making between clinician and patient. This is where the resources of phenomenology become important alongside the established processes of VBP. For it is by way of phenomenological insights that implicit values inherent in a patient's values hierarchy may become explicit.

Step 1 (analysis of conflicting values) in our three-step process can thus be thought of as comprising two levels. The first level involves enhanced understanding of the values included in a patient's hierarchy. Where these values are explicit this can be achieved essentially by exercising the (learnable) clinical skills of values-based practice. But analyzing the implicit values requires the additional insights of phenomenology. In other areas of clinical work, understanding the explicit values involved may be sufficient. This is true for example in many areas of surgical decision-making (Handa et al., 2016). But as Marcos' story illustrates, with SUD, effective decision-making may depend on understanding not only the explicit but also the implicit values involved. It is here that the enriched understanding offered by Phenomenological Psychopathology comes into 6 play. For it, only once the conflicting values (implicit as well as explicit) are identified is the patient (sometimes 
with relatives and other stakeholders and sometimes on their own) empowered to work in a process of shared decision-making with the clinician based on an understanding of his or her own hierarchy of values.

\section{Step 2 - Values-enriched phenomenological psychopathological understanding}

The above values-based insights into the values likely to be conflicting between Marcos and his family/ society allow a values-enriched phenomenological psychopathological understanding of his story. Thus, the fact that the patient continues in his successful professional trajectory, despite the objectively verified important cognitive losses, shows the almost exclusive relevance that Marcos' professional identity has at this moment of his existence. The evaluation he makes of himself, with which he justifies his decisions regarding alcohol, is based on the history of his professional success. It is important to emphasize that the fact that he has been practicing his profession for many years strengthens the automatic maintenance of that identity. The very sustainability of his professional identity depends rather on an incorporated habit than on an impulse to expand professionally, whether in economic terms or in search of social relevance. Thus, the way that Marcos' existence is supported by his professional identity would not seem tenable if there was a negative change in his work situation brought about by his alcohol consumption, as his family and friends fear.

Marcos' refusal to change his behavior in response to any of the suggestions of his family and friends indicates high personal rigidity and a restriction of existential temporality to the present dimension. This rigidity, in turn, derives from the low relative participation of intersubjectivity in his existence. Consequently, Marcos shows an inability to consider and adapt to the perceptions of his closest peers, further reinforcing the need for hegemonic existential support in his professional identity. At this moment in his life, Marcos is increasingly just his professional identity.

\section{Step 3 - The clinical decision-making process by VBPh}

The values-enriched phenomenological psychopathological understanding of Marcos' story outlined above in Step-2 informs the process of clinical decision-making. To anticipate, phenomenology provides insightful understanding of the hierarchy of values driving Marcos' life choices. But as in so many other similar stories of patients with SUD, the values by which Marcos' hierarchy is comprised are complex and conflicting. Thus, effective clinical decision-making depends on balancing the tensions between these complex and conflicting values. This balancing of values (which is made possible by the exercise of learnable valuesbased clinical skills) is the essence of what VBP adds to a phenomenologically informed process of clinical decision-making (Fulford et al., 2012).

The starting point for clinical decision-making in this case is that as Marcos does not present any impairment in his ability to judge reality, any decisions in respect of his treatment must (according to contemporary standards of medical ethics and law) follow his wishes, established after discussion with family members. This, however, as we have seen, is precisely where conflicts arise between Marcos' values and those of his family and the wider society. The patient intends to continue drinking despite the risks pointed out by his family and the clinician. If he has to choose, he will maintain his pleasurable drinking habit and put up with the losses this brings to his relationships and to himself. Thus, he has established a hierarchy of values in favor of his personal independence and decisional autonomy, with indifference to the opinions of those closest to him.

This is where, as noted above, the skills and other resources of VBP for balanced clinical decision-making come into play alongside those of phenomenology. Phenomenological psychopathological comprehension of the situation deepened the understanding of this conflict, presenting the structural bases on which Marcos'

free decision took place. Using a VBPh approach, the sense of personal values is understood from its conditions 
of possibility. From this perspective, one can say that Marcos opts to maintain the integrity of his existence based almost exclusively on his professional identity. Hegemonic reinforcement of one of the conditions of possibility of existence favors the weakening of the other conditions of possibility, notably his closest intersubjective relations. He opts for this choice even in the face of the risk of destroying his marriage, an event that would further reduce his existential support in the world and would demand further reinforcement of his professional identity. In short, from a phenomenological point of view, Marcos' decision represents an existential movement of growing investment in the supremacy of a single personal identity, leading to an anthropological disproportion (Messas, 2021) with a corresponding increase in existential vulnerability, due to the lack of support in other dimensions.

\section{A balanced approach to meeting Marcos' existential needs}

Once the patient is informed of the phenomenological meaning of his decisions, he can decide, together with the clinician and family members, the least harmful way to manage his behaviors in order to voluntarily move toward a situation of growing vulnerability. With the phenomenological contribution, these decisions become informed by an expanded sense of personal agency. The patient's decision becomes understood no longer as merely seeking for autonomy, but rather as a voluntary reinforcement of a condition of anthropological disproportion.

This allows the patient, clinicians, and family members to make the important strategic decisions necessary to achieve this difficult objective by fostering the following three specific existential needs of Marcos: (a) Increased care in the preservation of professional identity: If his existence depends more and more on this identity, it is vital that the first objective of clinical decisions should be to prevent the patient from taking risks that damage his professional image through inappropriate behaviors related to alcoholism (Note: it is important to emphasize that the exercise of his profession does not imply immediate risks to third parties) and to support him in the best possible performance of his role, in the face of the risks of disintegration that alcoholism brings; (b) Preservation of the functionality of his professional identity: In order for the above item to be carried out as effectively as possible, it is important that automatic acts of daily working life - particularly those strictly related to Marcos' job description and which no longer require creativity, but arise as a prereflexive habit -, have priority in his work tasks. At work, he should try to avoid positions or functions that involve behavioral innovations that require cognitive plasticity, as this is quite reduced, and demands of this nature may make the existing cognitive deficit visible, ultimately compromising the previous strategy; and (c) a voluntary effort on the part of Marcos to offer greater participation and openness to intersubjectivity, especially to his family, seeking the multiplicity of perspectives that this increase brings. It is characteristic of SUD psychopathology to reduce the ability to experience the dialectical complexities of situations (Messas et al., 2019). This existential condition restricts the power of appreciation of oneself and of the world, by favoring a unilateral subjectivism enclosed within oneself. The inclusion of subjectivities that bring more perspectives on his life serves as an antidote to the closure of his historical self in his own solipsistic subjectivity.

\section{Summary of the impact of three-step process of VBPh}

Building on a phenomenological appreciation of the conflicting values that hindered his strategic treatment decisions, Marcos comes to understand the pre-reflexive dimensions involved in his decision, and, consequently, is able to orient himself and the clinician by reference to them. The final result of the exercise of the three-step process of VBPh in Marcos' story is thus an enhanced capacity for the efficient exercise of shared decision-making between patient and clinician, enhanced by a better understanding of the existential meaning of the conflicts inherent in Marcos' personal hierarchy of values. 


\section{Conclusion}

Clinical decision-making is the fruit of a complex process, in which knowledge-based strategies should be adapted to patients' personal values and social context if they are to be fully effective. Due to the complexity of this process, a gap is often observed between the supply of services and the needs and other values subjectively experienced by patients. This gap is particularly evident in SUD where, as in Marcos' story, the patient's values are in direct conflict with those of the clinician (and the patient's family). We have argued that a promising strategy for reducing this gap and thus increasing clinical effectiveness in the field of SUD care is the association of Phenomenological Psychopathology with values-based practice, constituting a new discipline, values-based phenomenology (VBPh).

We presented a clinical case, Marcos', a fictitious case based on an amalgam of real cases, illustrating the basic dynamics of values and psychopathological findings. As Marcos' story indicated, VBPh follows three key steps, analysis of values, values-enriched phenomenological understanding, and clinical decisionmaking. In the first step, the multiple value conflicts involved in clinical decisions in SUD are analyzed using the skills of values-based practice enhanced with phenomenological insights. In the second step, the values identified and elected as central to the treatment undergo a comprehensive phenomenological analysis, in which their meanings for existence are dissected in terms of their structure. Through this analysis, the patient and the family/stakeholders can better understand the existential meaning of the decisions taken and their consequences for their whole existence. Finally, in the third and last step, the analysis of values undergoes a comprehensive phenomenological analysis, allowing the elaboration of clinical decisions to follow the wills and values of the patient and, at the same time, explain the existential dimensions of the valuation options. This is shared decision-making in action. For the association of psychopathology with the analysis of values allows the best clinical strategy to be adapted to the strategies chosen by the patient in consultation with the clinician.

Although VBPh is still a nascent discipline, the clinical example above demonstrates how its application can contribute to the construction of effective clinical care in a mental health sector as multifaceted as SUD, while taking into account both the scientific evidence and the values (the desires and conflicts) of the patient and their family members. VBPh supports this effort by investigating in depth and illuminating the global existential meanings involved in clinical strategies. Using this method, we intend to develop clinical care based on a phenomenologically enhanced values-based model of shared clinical decision-making that avoids a merely superficial treatment of the existential complexities involved in so many human actions and decisions. This new VBPh model allows clinical decision-making to offer complex solutions to necessarily complex issues.

\section{Contributors}

G. MESSAS was responsible for conceptualization, data curation, formal analysis, supervision, writing the original draft, and review and editing. K. FULFORD was responsible for conceptualization, formal analysis, methodology, supervision, validation, and writing, review and editing.

\section{References}

American Psychiatric Association. (2013). Diagnostic and statistical manual of Mental Disorders (5th ed.). Arlington: American Psychiatric Publishing.

Arria, A. M., \& McLellan, A. T. (2012). Evolution of concept, but not action, in addiction treatment. Substance Use and Misuse, 47, 1041-1048. https://doi.org/10.3109/10826084.2012.663273

Cury, V. E. (2016). Thematic section: Psychology and Phenomenology: a field of interlocution in constant transformation. Estudos de Psicologia (Campinas), 33(3), 381-382. https://doi.org/10.1590/1982-02752016000300001a 
Cuthbert, B. N. (2014). The RDoC framework: facilitating transition from ICD/DSM to dimensional approaches that integrate neuroscience and psychopathology. World Psychiatry, 13(1), 28-35. https://doi.org/10.1002/wps.20087

Di Petta, G., \& Tittarelli, D. (2019). The "We-Ness": a Dasein-Analytical approach to group therapy. Psychopathology, 52(2), 110-116. https://doi.org/10.1159/000501954

Fuchs, T., Messas, G., \& Stanghellini, G. (2019). More than just description: phenomenology and psychotherapy. Psychopathology, 52(2), 63-66. https://doi.org/10.1159/000502266

Fulford, K. W. M. (1999). Moral theory and medical practice. Cambridge: Cambridge University Press (Original work published 1989).

Fulford, K. W. M., Broome, M., Stanghellini, G., \& Thornton, T. (2005). Looking with both eyes open: fact and value in psychiatric diagnosis? World Psychiatry, 4(2), 78-86.

Fulford, K. W. M., Dewey, S., \& King, M. (2015). Values-based involuntary seclusion and treatment: value pluralism and the UK's mental health Act 2007. In J. Z., Sadler, W. van Staden, \& K. W. M. Fulford (Eds.), The Oxford Handbook of Psychiatric Ethics (pp. 839-860). Oxford: Oxford University Press.

Fulford, K. W. M., Peile, E., \& Carroll, H. (2012). Essential values-based practice: clinical stories linking science with people. Cambridge: Cambridge University Press.

Fulford, K. W. M., \& Stanghellini, G. (2019). Values and valus-based practice. In G. Stanghellini, M. Broome, A. V. Fernandez, P. Fusar-Poli, A. Raballo, \& R. Rosfort (Eds.), Oxford Handbook of Phenomenological Psychopathology (pp. 354-366). Oxford: Oxford University Press. https://doi.org/10.1093/oxfordhb/9780198803157.013.40

Fulford, K. W. M., \& van Staden, W. (2013). Values-based practice: topsy-turvy take home messages from ordinary language philosophy (and a few next steps). In K. W. M. Fulford, M. Davies, R. Gipps, G. Graham, J. Sadler, G. Stanghellini, \& T. Thornton (Eds.), The Oxford Handbook of Philosophy and Psychiatry (pp. 385-412). Oxford: Oxford University Press.

Handa, I. A., Fulford-Smith, L., Barber, Z. E., Dobbs, T. D., Fulford, K. W. M., \& Peile, E. (2016). The importance of seeing things from someone else's point of view. BMJ, 354, i1652. https://doi.org/10.1136/bmj.i1652

Hall, W., Carter, A., \& Forlini, C. (2015). The brain disease modelo faddiction: is it supported bt the evidence and has it delivered on its promises? Lancet Psychiatry, 2(1), 105-110. https://doi.org/10.1016/\$2215-0366(14)00126-6

Holanda, A. F. (2016). Fenomenologia e Psicologia no Brasil: aspectos históricos. Estudos de Psicologia (Campinas), 33(3), 383-394. https://doi.org/10.1590/1982-02752016000300002

Jaspers, K. (1997). General Psychopathology. Baltimore: Johns Hopkins University Press.

Joosten, E. A., Jong, C. A., Weert-van Oene, G. H., Sensky, T., \& van der Staak, C. P. (2011). Shared decision-making: increases autonomy in substance-dependent patients. Substance Use and Misuse, 46(8), 1037-1048. https://doi.org $/ 10.3109 / 10826084.2011 .552931$

Kemp, R., \& Butler, A. (2014). Love, hate and the emergence of self in addiction recovery. Existencial Analysis, 252, 257-268.

Kupfer, D. J., First, M. B., \& Regier, D. E. (2002). Introduction. In D. J. Kupfer, M. B. First, \& D. E. Regier (Eds.), A research agenda for DSM-V (pp. 15-23). Washington: American Psychiatric Association.

Leal, E. M., Muñoz, N. M., \& Serpa, O. D., Jr. (2019). Além da compulsão e da escolha: autonomia, temporalidade e recuperação pessoal. Revista Latinoamericana de Psicopatologia Fundamental, 22(1), 130-149. https://doi. org/10.1590/1415-4714.2018v22n1p130.8

Messas, G. (2015). A existência fusional e o abuso de crack. Psicopatologia Fenomenológica Contemporânea, 4(1), 124140. https://doi.org/10.37067/rpfc.v4i1.1004

Messas, G. (2014a). O sentido da fenomenologia na psicopatologia geral de Karl Jaspers. Psicopatologia Fenomenológica Contemporânea, 3(1), 23-47.

Messas, G. (2014b). Psicose e embriaguez: psicopatologia fenomenológica da temporalidade. São Paulo: Editora Intermeios.

Messas, G. (2021). The existential structure of substance misuse: a psychopathological study. Cham: Springer Nature.

Messas, G., Fukuda, L., \& Pienkos, E. (2019). A phenomenological contribution to substance misuse treatment: principles for person-centered care. Psychopathology, 52(2), 85-93. https://doi.org/10.1159/000501509

Messas, G., \& Soares, M. J. (2021). Alcohol use disorder in a culture that normalizes the consumption of alcoholic beverages: the conflicts for decision-making. In D. Stoyanov, G. Stanghellini, W. van Staden, M. T. Wong, \& K. W. M. Fulford (Eds.), International perspectives in values-based mental health practice: case studies and commentaries (pp. 163-170). Berlin: Springer Nature. https://doi.org/10.1007/978-3-030-47852-0_19

Messas, G., Tamelini, M., Mancini, M., \& Stanghellini, G. (2018). New perspectives in phenomenological psychopathology: its use in psychiatric treatment. Front Psychiatry, 9(466), 1-5. https://doi.org/10.3389/fpsyt.2018.00466 
Moreira, V. (2013). Uma perspectiva histórica da psicopatologia fenomenológica. Fenomenologia e Psicologia, 1(1), 123-128.

Pringuey, D. (2005). Une phénoménologie de la dépendance à l'alcool: une expérience primordiale de la "nostrité". L'Évolution Psychiatrique, 70(4), 771-779. https://doi.org/10.1016/j.evopsy.2005.10.004

Sadler, J. Z. (2005). Values and psychiatric diagnosis. Oxford: Oxford University Press.

Scheler, M. (1980). Der Formalismus in der Ethik und die materiale Wertethik (Vol. 2). München: Ges.

Stanghellini, G., \& Ballerini, M. (2007). Values in persons with schizophrenia. Schizophrenia Bulletin, 33(1), 131-141. https://doi.org/10.1093/schbul/sbl036

Stanghellini, G., Broome, M., Fernandez, A., Fusar Poli, P., Raballo, A., \& Rosfort, R. (2019). Oxford handbook of phenomenological psychopathology. Oxford: Oxford University Press.

Stanghellini, G., \& Mancini, M. (2017). The therapeutic interview in mental health: a values-based and person-centered approach. Cambridge: Cambridge University Press.

Stanghellini, G., Mancini, M., Castellini, G., \& Ricca, V. (2018). Eating disorders as disorders of embodiment and identity. theoretical and empirical perspectives. In H. L. McBride, \& J. L. Kwee (Eds.), Embodiment and eating disorders: theory, research, preventions and treatment (pp. 127-142). London: Routledge.

Tamelini, M. G., \& Messas, G. P. (2017). Phenomenological psychopathology in contemporary psychiatry: interfaces and perspectives. Revista Latinoamericana de Psicopatologia Fundamental, 20(1), 165-180. https://doi.org/10.1590/14154714.2017v20n1p165.11

Tamelini, M. G., \& Messas, G. P. (2019). Pharmacological treatment of schizophrenia in light of phenomenology. Philosophy, Psychiatry, and Psychology, 26(2), 133-142. https://doi.org/10.1353/ppp.2019.0017

World Health Organization. (1999). International statistical classification of diseases and related health problems (10th ed.). Geneva: World Health Organization.

Received: June, 9, 2020

Final version: July, 22, 2020

Approved: September 3, 2020 